\title{
Exposure to Indoor Particulate Matter Worsens the Symptoms and Acute Exacerbations in Chronic Obstructive Pulmonary Disease Patients of Southwestern Taiwan: A Pilot Study
}

\author{
Miao-Ching Chi ${ }^{1,2}$, Su-Er Guo ${ }^{1,3,4, *}$, Su-Lun Hwang ${ }^{1,3}$, Chiang-Ting Chou 1,3, \\ Chieh-Mo Lin 2,4,5 and Yu-Ching Lin ${ }^{2,4,6}$ \\ 1 Chronic Diseases and Health Promotion Research Center, Chang Gung University of Science and \\ Technology (CGUST), Puzi City 613, Taiwan; mcchi@mail.cgust.edu.tw (M.-C.C.); \\ slhuang@mail.cgust.edu.tw (S.-L.H.); ctchou@gw.cgust.edu.tw (C.-T.C.) \\ 2 Department of Respiratory Care, Chang Gung University of Science and Technology, Puzi City 613, Taiwan; \\ f124510714@adm.cgmh.org (C.-M.L.); lin0927@adm.cgmh.org.tw (Y.-C.L.) \\ 3 Department of Nursing, Chang Gung University of Science and Technology, Chiayi Campus, \\ Puzi City 613, Taiwan \\ 4 Division of Pulmonary and Critical Care Medicine, Chang Gung Memorial Hospital, Puzi City 613, Taiwan \\ 5 Graduate Institute of Clinical Medical Sciences, College of Medicine, Chang Gung University, \\ Taoyuan 333, Taiwan \\ 6 Department of Respiratory Care, Chang Gung University, Taoyuan 333, Taiwan \\ * Correspondence: seguo@mail.cgust.edu.tw; Tel.: +886-5-362-8800 (ext. 2331)
}

Academic Editor: Paul B. Tchounwou

Received: 22 October 2016; Accepted: 19 December 2016; Published: 22 December 2016

\begin{abstract}
Ambient particulate matter (PM) can trigger adverse reactions in the respiratory system, but less is known about the effect of indoor PM. In this longitudinal study, we investigated the relationships between indoor PM and clinical parameters in patients with moderate to very severe chronic obstructive pulmonary disease (COPD). Indoor air quality ( $\mathrm{PM}_{2.5}$ and $\mathrm{PM}_{10}$ levels) was monitored in the patients' bedroom, kitchen, living room, and front door at baseline and every two months for one year. At each home visit, the patients were asked to complete spirometry and questionnaire testing. Exacerbations were assessed by chart review and questionnaires during home visits. Generalized estimating equation (GEE) analysis $(n=83)$ showed that the level of wheezing was significantly higher in patients whose living room and kitchen had abnormal (higher than ambient air quality standards in Taiwan) $\mathrm{PM}_{2.5}$ and $\mathrm{PM}_{10}$ levels. Patients who lived in houses with abnormal outdoor $\mathrm{PM}_{2.5}$ levels had higher COPD Assessment Test scores (physical domain), and those who lived in houses with abnormal $\mathrm{PM}_{10}$ levels in the living room and kitchen had higher London Chest Activity of Daily Living scores. Increased PM levels were associated with worse respiratory symptoms and increased risk of exacerbation in patients with moderate to very severe COPD.
\end{abstract}

Keywords: indoor air quality; COPD assessment test; acute exacerbation of COPD (AECOPD); hospitalization; respiratory symptoms; chronic obstructive pulmonary disease

\section{Introduction}

Ambient particulate matter (PM) can have a negative impact on respiratory diseases [1], increasing their prevalence [2] and the number of associated hospital admissions [3]. In particular, ambient PM is directly associated with mortality rate [4] and risk of acute exacerbation in chronic obstructive pulmonary disease (COPD) [5-8]. $\mathrm{PM}_{2.5}$ with a mean aerodynamic diameter of $\leq 2.5 \mu \mathrm{m}$ is more likely to cause respiratory diseases than $\mathrm{PM}_{10}$ with a mean aerodynamic diameter of $\leq 10 \mu \mathrm{m}$. $\mathrm{PM}_{10}$ is the 
most commonly associated with sea salt, road/soil dust, and construction activities, whereas $\mathrm{PM}_{2.5}$ is associated with transformation of gaseous species, industrial combustion processes, and forest fires [9].

Acute exacerbation (AE) is a major cause of death [10] and impaired quality of life in patients with COPD [11,12], an increased burden of medical and social resources, and increased expenditures by families and governments [13]. The probability of AE differs greatly among patients with COPD. A previous history of medically recorded treatments for patients with acute exacerbation of COPD (AECOPD) predicts the possibility of having frequent AEs ( $\geq 2$ times in a year) [14]. Frequent AEs in patients with COPD induce loss of lung function $[15,16]$, promote a decline in daily activities [17], and worsen dyspnea, ultimately causing disability $[16,18]$. Dominici et al. reported that elevated levels of $\mathrm{PM}_{2.5}$ in 204 cities of the United States were associated with a significant increase of hospital admissions in patients with COPD on the same day of exposure (lag0) and an increase of hospital admissions in patients with heart failure the next day of exposure (lag1), suggesting $\mathrm{PM}_{2.5}$ has a negative and immediate impact on AE in patients with COPD [3].

Although some studies have demonstrated that ambient PM is associated with morbidity, admission rate, and mortality of respiratory diseases, few studies have investigated the effects of indoor PM on the symptoms, lung function, and AEs in patients with COPD. The prevalence of respiratory diseases has been increasing worldwide during the past decade. In 2012, respiratory diseases were the third leading global cause of death worldwide [19]. The Ministry of Health and Welfare of the Republic of China indicated that in 2014, the COPD-related standardized death rate in Taiwan was 15.3 deaths per 100,000 individuals, which is lower than that in the Unites States (24.7 deaths per 100,000 individuals), but higher than that in Asian neighbors such as Japan, Singapore, and Korea [20]. In the Chiayi County of Taiwan, the standardized death rate of COPD was 16.4 deaths per 100,000 individuals, and COPD was the seventh leading cause of death (the sixth in males and the tenth in females) [21]. The purpose of this study was to investigate the relationships between PM levels at home and clinical parameters in patients with moderate to very severe COPD.

\section{Materials and Methods}

\subsection{Study Design}

A longitudinal design was used in the present study. The frequency of home visits for each participant was every two months in one year (for a total of six visits). In this study, all participants were patients with AECOPD and were recruited from outpatient clinics of the division of Pulmonary and Critical Care Medicine in a regional hospital in southwestern Taiwan from March 2014 to May 2016. This study was approved by the Ethical Committee of the Human Body of the Chang Gung Medical Foundation (102-2417B). After explaining the purpose and procedure to possible participants, informed consent was obtained from all subjects who were willing to take part in the study. After that, home visits for data collection were arranged, including interviewer-administered questionnaires and environmental data collection through observation and equipment. In addition, to avoid the preparation of meals, we made each visit between 9 a.m. and 11 a.m. or 2 p.m. and 4 p.m.

\subsection{Participants}

Inclusion criteria were as follows: (1) age $\geq 40$ years; (2) COPD diagnosis by physicians and hospital admission of $\mathrm{AE} \geq 1$ time within the previous 3 months; (3) moderate to very severe COPD according to Global Initiative for Chronic Obstructive Lung Disease (GOLD) guidelines (forced expiratory volume in 1 second $\left[\mathrm{FEV}_{1}\right]$ predicted $<80 \%$ ) [15]; and (4) ability to understand and communicate in Chinese or Taiwanese. We excluded patients with heart disease, asthma, tuberculosis, or cancer.

\subsection{Measurements and Instruments}

This study was designed using a structured self-reported questionnaire that was divided into four sections: demographic and clinical characteristics, respiratory symptoms, COPD Assessment 
Test (CAT), and London Chest Activity of Daily Living (LCADL) scale. The number of emergency room (ER) visits or hospital admissions was collected by chart review. Environmental data (air quality assessment) included $\mathrm{PM}_{2.5}$ and $\mathrm{PM}_{10}$ levels.

\subsubsection{Demographic and Clinical Characteristics}

Demographics included age, gender, weight status, employment status, education level, exercise habits, smoking status, family smoking, living environment, disease severity, body mass index (BMI), and waist-to-hip ratio. Clinical characteristics included Charlson comorbidity index (CCI), FEV 1 at first visit, and length of COPD diagnosis in years. FEV 1 at every visit was considered, as a confounding variable in the analysis of the association between PM levels and the symptoms and acute exacerbations of COPD patients. The CCI is used as a measurement of the 1-year mortality risk, and includes 19 comorbidities. The CCI scores are 0 (no symptoms), 1, 2, 3, or 6 per item. Higher CCI scores indicate a higher level of burden of the disease.

\subsubsection{Respiratory Symptoms}

Respiratory symptoms were evaluated using a modified version of the symptoms section of the St. George's Respiratory Questionnaire (SGRQ). This section addresses the frequency of respiratory symptoms and uses a five-point Likert scale scoring for questions, with options of 0 (disagree strongly), 1 (disagree), 2 (no response), 3 (agree), and 4 (agree strongly). Higher scores indicate more respiratory problems experienced by patients. Cronbach's alpha of the Chinese version [22] and that of the version of the present study was 0.76 and 0.78 , respectively, indicating good reliability.

\subsubsection{COPD Assessment Test (CAT)}

The CAT consists of eight items related to COPD symptoms, including cough, phlegm (mucus), chest tightness, breathlessness after walking up a hill or one flight of stairs, activity limitation at home, confidence in leaving home, sleep quality, and energy. Each item is scored from 0 to 5 . A study of the Chinese version of CAT reported that the severity of lung function is associated with an increase of CAT score [23]. The Cronbach's alpha was 0.81, evidencing that the Chinese version of the CAT had good internal consistency [23]. The CAT in the Chinese version is a simple, reliable, and validated test for patients with COPD [23].

\subsubsection{London Chest Activity of Daily Living (LCADL) Scale}

The LCADL is divided into four categories (self-care, domestic, physical, and leisure) and consists of 17 items. Each item is scored from 0 to 5 points. It has been used to assess breathlessness during daily living activities in patients with heart diseases and COPD. Higher LCADL scores show greater limitation in daily living activities. The LCADL has good construct validity and concurrent validity with SGRQ, Extended Activities of Daily Living (EADL), the Shuttle test, and Forced Vital Capacity $(\mathrm{FVC})$ [24]. It is also a measuring tool with good reliability (Chronbach's alpha $=0.98)$.

\subsubsection{Acute Exacerbation}

We used the number of emergency room (ER) visits or COPD-related hospitalizations as an objective representation of AE. The number of ER visits and admissions were counted every 2 months using chart review.

\subsubsection{Air Quality Assessment}

Outdoor and indoor air sampling for $\mathrm{PM}_{2.5}$ and $\mathrm{PM}_{10}$ was performed by using an aerosol spectrometer (Model TSI8532) at every home visit. We detected $\mathrm{PM}_{2.5}$ and $\mathrm{PM}_{10}$ in four areas, including the front of the house (outside the front door), living room, bedroom, and kitchen. Each detection was performed three times for $1 \mathrm{~min}$. The daily mean or $24-\mathrm{h}$ maximum of $\mathrm{PM}_{10}$ is $125 \mu \mathrm{g} / \mathrm{m}^{3}$, and that of 
$\mathrm{PM}_{2.5}$ is $35 \mu \mathrm{g} / \mathrm{m}^{3}$ according to the 2012 Environment Protection Administration of Taiwan ambient air quality standards [25].

\subsection{Statistical Analyses}

Demographic and clinical characteristics are presented as number and percentage or mean and standard deviation. Due to repeated measurements (each patient was followed for a minimum of two sessions and a maximum of seven) in this study, we performed a generalized estimating equation (GEE) to account for the outcome dependency within subjects [26]. In the GEE analysis, we treated the air quality status at various areas (e.g., normal/abnormal outdoor levels of $\mathrm{PM}_{2.5}$ ) as independent variables with adjustment for control variables (age at baseline, $\mathrm{FEV}_{1}$ predicted at each visit, smoking status, and whether the window was open or not). Normal PM levels were defined as per Taiwan ambient air quality standards. There were two types of outcome measures: the subjective measures (i.e., CAT, LCADL) and the objective measures (i.e., the number of ER visits or admissions due to AE of COPD). We conducted data analyses using SPSS 22 (IBM Corp., Armonk, NY, USA).

\section{Results}

\subsection{Patient Characteristics}

Twenty-six participants were initially included. Seven participants were excluded because they withdrew their consent during the study period. There was no statistically significant difference between the included $(n=19)$ and excluded $(n=7)$ participants in variables such as age, gender, BMI, and lung function. In total, data from 19 participants were collected every 2 months. However, some participants did not complete the six home visits because of hospitalization, travel to another city, or death. In total, we collected data from 83 home visits. All 19 participants were male and their mean age was $72.6 \pm 6.8$ years. Most of them were farmers (42.1\%), $57.9 \%$ were living with their children or spouses, and all of them believed in Taoism. Mean BMI was $22.7 \pm 6.7$, mean disease duration was 5.1 years, mean $\mathrm{FEV}_{1}$ at the first visit was $42.4 \%$, and mean waist-to-hip ratio was $1.00 \pm 0.11$ (Table 1 ).

Table 1. Demographic and clinical characteristics of the study participants $(n=19)$.

\begin{tabular}{lc}
\hline Variable & $n \mathbf{( \% )}$ or Mean \pm Standard Deviation (SD) \\
\hline Gender & $19(100.0)$ \\
$\quad$ Male & \\
\hline Weight status & $5(26.3)$ \\
Underweight & $8(42.1)$ \\
Normal & $3(15.8)$ \\
Overweight & $3(15.8)$ \\
Obese & \\
\hline Employment status & $2(10.5)$ \\
Part-time job & $17(89.5)$ \\
$\quad$ Retired & \\
\hline Education level & $3(15.8)$ \\
Uneducated & $10(52.6)$ \\
Elementary school & $6(31.6)$ \\
Junior high school or above & \\
\hline Regular exercise & $14(73.7)$ \\
No & $5(26.3)$ \\
$\quad$ Yes & $14(73.7)$ \\
\hline Cigarette smoking & $5(26.3)$ \\
Quit & \\
Current smoker &
\end{tabular}


Table 1. Cont.

\begin{tabular}{|c|c|}
\hline Variable & $n(\%)$ or Mean \pm Standard Deviation (SD) \\
\hline \multicolumn{2}{|l|}{ Family smoking } \\
\hline No & $10(52.6)$ \\
\hline Yes & $8(42.1)$ \\
\hline Sometimes & $1(5.3)$ \\
\hline \multicolumn{2}{|l|}{ Whether the window was open or not } \\
\hline Always open & $10(52.6)$ \\
\hline Always closed & $8(42.1)$ \\
\hline Sometimes & $1(5.3)$ \\
\hline \multicolumn{2}{|l|}{ Disease severity * } \\
\hline Moderate & $6(31.6)$ \\
\hline Severe & $8(42.1)$ \\
\hline Very severe & $5(26.3)$ \\
\hline Age (years) & $72.6 \pm 6.8$ \\
\hline Body mass index (BMI) $\left(\mathrm{kg} / \mathrm{m}^{2}\right)$ & $22.7 \pm 6.7$ \\
\hline Waist-hip ratio & $1.00 \pm 0.11$ \\
\hline Charlson comorbidity index (CCI) $\#$ & $5.7 \pm 1.1$ \\
\hline $\mathrm{FEV}_{1}$ at 1 st visit $(\%)$ & $42.4 \pm 15.0$ \\
\hline $\begin{array}{l}\text { Chronic obstructive pulmonary disease } \\
\text { (COPD) duration (years) }\end{array}$ & $5.1 \pm 2.9$ \\
\hline
\end{tabular}

Note: ${ }^{*}$ Based on guideline of Global Initiative for Chronic Obstructive Lung Disease (GOLD), moderate $\left(79 \% \leq \mathrm{FEV}_{1}\right.$ predicted $\left.\leq 50 \%\right)$; severe $\left(49 \% \leq \mathrm{FEV}_{1 \text { predicted }} \leq 30 \%\right)$; very severe $\left(\mathrm{FEV}_{1 \text { predicted }}<30 \%\right)$. " Higher $\mathrm{CCI}$ scores indicate a higher level of burden of disease.

\section{2. $P M_{2.5}$ and $P M_{10}$ Concentrations and Abnormal Proportions}

Mean $\mathrm{PM}_{2.5}$ concentrations for the bedroom, kitchen, main living area, and outdoor area were $104.7 \pm 66.5,119.0 \pm 74.4,104.7 \pm 66.5$, and $120.6 \pm 75.2 \mu \mathrm{g} / \mathrm{m}^{3}$, respectively. Mean $\mathrm{PM}_{10}$ concentrations for the bedroom, kitchen, main living area, and outdoor area were $104.6 \pm 66.8$, $123.4 \pm 77.3,114.6 \pm 66.8$, and $131.3 \pm 81.3 \mu \mathrm{g} / \mathrm{m}^{3}$, respectively. On average, most indoor and outdoor $\mathrm{PM}_{2.5}$ concentrations were abnormal (i.e., $>35 \mu \mathrm{g} / \mathrm{m}^{3}$ for $\mathrm{PM}_{2.5}$ and $>125 \mu \mathrm{g} / \mathrm{m}^{3}$ for $\mathrm{PM}_{10}$ ). The abnormal proportions of the bedroom, kitchen, main living area, and outdoor area were $0.85 \pm 0.17$, $0.89 \pm 0.19,0.86 \pm 0.16$, and $0.89 \pm 0.13$, respectively. However, only about half of indoor and outdoor $\mathrm{PM}_{10}$ concentrations were abnormal. The abnormal proportions for the bedroom, kitchen, main living area, and outdoor area were $0.46 \pm 0.35,0.43 \pm 0.29,0.46 \pm 0.32$, and $0.54 \pm 0.36$, respectively.

\subsection{Association between $P M_{2.5}$ Concentrations, Symptoms, and Activities of Daily Living (ADL)}

Table 2 shows the descriptive statistics of outcome measures according to normal or abnormal $\mathrm{PM}_{2.5}$ levels. GEE analysis showed that the level of wheezing was higher in patients living in houses with abnormal $\mathrm{PM}_{2.5}$ levels in the outdoors $(B=1.46, p<0.01)$, living room $(B=0.80, p<0.001)$ and kitchen $(B=1.03, p<0.01)$ than in those with normal $\mathrm{PM}_{2.5}$ levels. Patients living in houses with abnormal outdoor $\mathrm{PM}_{2.5}$ levels also had higher CAT physical scores $(B=0.93, p<0.05)$ than those living in houses with normal $\mathrm{PM}_{2.5}$ levels. However, there was no association between air quality and LCADL scores.

\subsection{Association between $P M_{10}$ Concentrations, Symptoms, and ADL}

Table 3 shows the descriptive statistics of outcome measures according to normal or abnormal $\mathrm{PM}_{10}$ levels. Similar to the results of $\mathrm{PM}_{2.5}$, the level of wheezing was higher in patients living in houses with abnormal $\mathrm{PM}_{10}$ levels in the living room $(B=0.36, p<0.05)$ and in the kitchen $(B=0.38$, $p<0.05)$ than in those with normal $\mathrm{PM}_{10}$ levels. GEE analysis also showed that the LCADL scores were higher in patients living in houses with abnormal $\mathrm{PM}_{10}$ levels in the living room $(B=5.58, p<0.05)$ and kitchen $(B=6.18, p<0.05)$. However, there was no association between air quality and CAT scores. 
Table 2. Association between $\mathrm{PM}_{2.5}$ level and the symptoms and activities of daily living (ADL) of chronic obstructive pulmonary disease (COPD) patients.

\begin{tabular}{|c|c|c|c|c|c|c|c|c|c|c|c|c|}
\hline \multirow[b]{2}{*}{ Variable } & \multicolumn{3}{|c|}{ Outdoor } & \multicolumn{3}{|c|}{ Living Room } & \multicolumn{3}{|c|}{ Bedroom } & \multicolumn{3}{|c|}{ Kitchen } \\
\hline & $\begin{array}{l}\text { Normal }^{\#} \\
(\text { obs }=6)\end{array}$ & $\begin{array}{l}\text { Abnormal * } \\
(\text { obs }=77)\end{array}$ & $B$ & $\begin{array}{l}\text { Normal }^{\#} \\
(\text { obs }=9)\end{array}$ & $\begin{array}{l}\text { Abnormal * } \\
(\text { obs }=74)\end{array}$ & $B$ & $\begin{array}{l}\text { Normal }^{\#} \\
(\text { obs }=13)\end{array}$ & $\begin{array}{l}\text { Abnormal * } \\
(\text { obs }=70)\end{array}$ & $B$ & $\begin{array}{l}\text { Normal }^{\#} \\
(\text { obs }=7)\end{array}$ & $\begin{array}{l}\text { Abnormal * } \\
(\text { obs }=76)\end{array}$ & $B$ \\
\hline \multicolumn{13}{|c|}{ Respiratory Symptoms } \\
\hline Cough & $3.8 \pm 1.8$ & $3.3 \pm 1.8$ & -0.20 & $3.8 \pm 1.9$ & $3.3 \pm 1.8$ & -0.56 & $3.4 \pm 1.9$ & $3.3 \pm 1.8$ & -0.10 & $3.4 \pm 2.0$ & $3.3 \pm 1.8$ & -0.57 \\
\hline Phlegm & $4.2 \pm 1.3$ & $3.5 \pm 1.8$ & -0.22 & $3.8 \pm 1.9$ & $3.5 \pm 1.8$ & -0.49 & $3.5 \pm 1.8$ & $3.5 \pm 1.8$ & -0.12 & $3.7 \pm 1.7$ & $3.5 \pm 1.8$ & -0.64 \\
\hline Dyspnea & $2.2 \pm 1.6$ & $2.9 \pm 1.6$ & 0.84 & $3.1 \pm 1.9$ & $2.8 \pm 1.6$ & -0.32 & $2.8 \pm 1.8$ & $2.8 \pm 1.6$ & -0.10 & $2.0 \pm 1.5$ & $2.9 \pm 1.6$ & 0.48 \\
\hline Wheezing & $1.2 \pm 0.4$ & $2.3 \pm 1.5$ & $1.46^{* *}$ & $1.1 \pm 0.3$ & $2.4 \pm 1.6$ & $0.80^{* * *}$ & $1.5 \pm 1.2$ & $2.4 \pm 1.5$ & 0.45 & $1.1 \pm 0.4$ & $2.3 \pm 1.5$ & 1.03 ** \\
\hline Total & $11.3 \pm 4.1$ & $12.0 \pm 4.8$ & 1.88 & $11.8 \pm 4.5$ & $11.9 \pm 4.8$ & -0.62 & $11.3 \pm 5.3$ & $12.0 \pm 4.6$ & 0.09 & $10.3 \pm 4.6$ & $12.1 \pm 4.7$ & 0.00 \\
\hline \multicolumn{13}{|c|}{$\begin{array}{l}\text { COPD Assessment Test } \\
\text { (CAT) }\end{array}$} \\
\hline Physical & $7.2 \pm 4.0$ & $7.8 \pm 4.2$ & $0.93 *$ & $8.1 \pm 4.7$ & $7.8 \pm 4.2$ & -0.16 & $8.3 \pm 5.0$ & $7.7 \pm 4.1$ & -0.82 & $5.7 \pm 4.0$ & $8.0 \pm 4.2$ & 0.16 \\
\hline Psycho & $2.7 \pm 2.0$ & $3.1 \pm 2.7$ & 0.04 & $2.6 \pm 2.0$ & $3.1 \pm 2.7$ & 0.61 & $2.8 \pm 2.0$ & $3.1 \pm 2.7$ & 0.12 & $1.7 \pm 1.7$ & $3.2 \pm 2.7$ & 0.15 \\
\hline Total & $9.8 \pm 5.9$ & $10.9 \pm 6.5$ & 0.93 & $10.8 \pm 6.7$ & $10.9 \pm 6.5$ & 0.34 & $11.2 \pm 7.0$ & $10.8 \pm 6.4$ & -0.81 & $7.4 \pm 5.7$ & $11.2 \pm 6.5$ & 0.23 \\
\hline \multicolumn{13}{|l|}{ London ADL } \\
\hline Self-care & $21.0 \pm 6.0$ & $20.3 \pm 4.8$ & 0.17 & $18.1 \pm 7.5$ & $20.6 \pm 4.4$ & 2.15 & $18.5 \pm 6.5$ & $20.7 \pm 4.5$ & 1.98 & $21.9 \pm 5.8$ & $20.2 \pm 4.8$ & 0.69 \\
\hline Domestic & $22.3 \pm 17.3$ & $19.6 \pm 13.7$ & -1.28 & $17.6 \pm 13.2$ & $20.1 \pm 14.0$ & 4.26 & $18.0 \pm 14.6$ & $20.1 \pm 13.8$ & 3.77 & $21.7 \pm 15.0$ & $19.6 \pm 13.8$ & 2.19 \\
\hline Sport & $3.2 \pm 2.7$ & $4.0 \pm 2.4$ & 0.38 & $4.2 \pm 3.7$ & $3.9 \pm 2.2$ & -0.53 & $4.4 \pm 3.5$ & $3.9 \pm 2.2$ & -0.83 & $2.4 \pm 2.7$ & $4.1 \pm 2.3$ & 0.07 \\
\hline Leisure & $1.5 \pm 3.2$ & $1.4 \pm 1.8$ & -0.15 & $2.0 \pm 2.8$ & $1.4 \pm 1.8$ & -0.56 & $1.8 \pm 2.4$ & $1.4 \pm 1.8$ & -0.32 & $1.3 \pm 3.0$ & $1.4 \pm 1.8$ & -0.34 \\
\hline Total & $48.0 \pm 17.5$ & $45.3 \pm 13.9$ & -0.84 & $41.9 \pm 14.1$ & $46.0 \pm 14.1$ & 5.27 & $42.7 \pm 15.0$ & $46.1 \pm 13.9$ & 4.55 & $47.3 \pm 15.4$ & $45.4 \pm 14.0$ & 2.63 \\
\hline
\end{tabular}

Note: $B=$ regression coefficient derived from the generalized estimating equation (GEE) model with adjustment for age at baseline, forced expiratory volume in 1 second (FEV 1 )

predicted at each visit, smoking status, and whether the window was open or not; obs = observation; \# Normal: Daily mean or $24-\mathrm{h}$ maximum of PM 10 is below $125 \mu \mathrm{g} / \mathrm{m}^{3}$, and that of

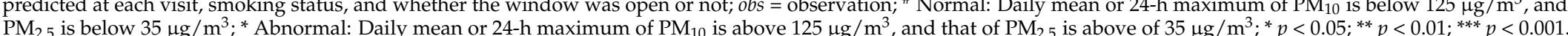


Table 3. Association between $\mathrm{PM}_{10}$ and the symptoms and activities of daily living of COPD patients.

\begin{tabular}{|c|c|c|c|c|c|c|c|c|c|c|c|c|}
\hline \multirow[b]{2}{*}{ Variable } & \multicolumn{3}{|c|}{ Outdoor } & \multicolumn{3}{|c|}{ Living Room } & \multicolumn{3}{|c|}{ Bedroom } & \multicolumn{3}{|c|}{ Kitchen } \\
\hline & $\begin{array}{l}\text { Normal \# } \\
(\text { obs }=43)\end{array}$ & $\begin{array}{c}\text { Abnormal * } \\
(\text { obs }=40)\end{array}$ & $B$ & $\begin{array}{l}\text { Normal }{ }^{\#} \\
(\text { obs }=46)\end{array}$ & $\begin{array}{c}\text { Abnormal * } \\
(\text { obs }=37)\end{array}$ & $B$ & $\begin{array}{l}\text { Normal } \\
(\text { obs }=50)\end{array}$ & $\begin{array}{c}\text { Abnormal * } \\
(\text { obs }=33)\end{array}$ & $B$ & $\begin{array}{l}\text { Normal } \\
(\text { obs }=46)\end{array}$ & $\begin{array}{c}\text { Abnormal * } \\
(\text { obs }=37)\end{array}$ & $B$ \\
\hline \multicolumn{13}{|c|}{ Respiratory Symptoms } \\
\hline Cough & $3.3 \pm 1.8$ & $3.4 \pm 1.9$ & -0.25 & $3.4 \pm 1.8$ & $3.2 \pm 1.8$ & -0.26 & $3.5 \pm 1.8$ & $3.2 \pm 1.9$ & -0.08 & $3.3 \pm 1.8$ & $3.4 \pm 1.8$ & -0.06 \\
\hline Phlegm & $3.4 \pm 1.7$ & $3.6 \pm 1.8$ & -0.07 & $3.5 \pm 1.7$ & $3.5 \pm 1.8$ & -0.24 & $3.6 \pm 1.7$ & $3.4 \pm 1.9$ & 0.04 & $3.4 \pm 1.7$ & $3.7 \pm 1.8$ & 0.02 \\
\hline Dyspnea & $2.6 \pm 1.6$ & $3.1 \pm 1.6$ & 0.40 & $2.7 \pm 1.7$ & $3.0 \pm 1.5$ & 0.39 & $2.8 \pm 1.7$ & $2.8 \pm 1.5$ & 0.13 & $2.6 \pm 1.7$ & $3.1 \pm 1.5$ & 0.25 \\
\hline Wheezing & $2.1 \pm 1.5$ & $2.4 \pm 1.6$ & 0.43 & $2.0 \pm 1.5$ & $2.5 \pm 1.5$ & $0.36^{*}$ & $2.1 \pm 1.6$ & $2.4 \pm 1.5$ & 0.18 & $2.0 \pm 1.5$ & $2.5 \pm 1.5$ & $0.38^{*}$ \\
\hline Total & $11.4 \pm 5.1$ & $12.5 \pm 4.2$ & 0.40 & $11.6 \pm 5.0$ & $12.3 \pm 4.3$ & 0.30 & $12.0 \pm 4.9$ & $11.8 \pm 4.5$ & 0.32 & $11.3 \pm 5.2$ & $12.7 \pm 4.0$ & 0.51 \\
\hline \multicolumn{13}{|l|}{ CAT } \\
\hline physical & $7.6 \pm 4.4$ & $8.0 \pm 4.1$ & -0.16 & $7.5 \pm 4.3$ & $8.2 \pm 4.1$ & 0.29 & $7.8 \pm 4.3$ & $7.8 \pm 4.1$ & 0.67 & $7.2 \pm 4.2$ & $8.5 \pm 4.1$ & 0.47 \\
\hline psycho & $2.7 \pm 2.4$ & $3.4 \pm 2.8$ & 0.20 & $2.7 \pm 2.4$ & $3.4 \pm 2.9$ & 0.41 & $2.9 \pm 2.5$ & $3.2 \pm 2.8$ & 0.10 & $2.5 \pm 2.2$ & $3.7 \pm 3.0$ & 0.67 \\
\hline Total & $10.3 \pm 6.5$ & $11.4 \pm 6.5$ & 0.00 & $10.2 \pm 6.3$ & $11.6 \pm 6.6$ & 0.65 & $10.7 \pm 6.5$ & $11.1 \pm 6.5$ & 0.75 & $9.8 \pm 6.1$ & $12.2 \pm 6.7$ & 1.10 \\
\hline \multicolumn{13}{|c|}{ London ADL } \\
\hline Self-care & $20.3 \pm 5.3$ & $20.4 \pm 4.4$ & 0.67 & $20.2 \pm 5.1$ & $20.6 \pm 4.5$ & 0.49 & $19.8 \pm 5.3$ & $21.2 \pm 3.9$ & 1.27 & $20.5 \pm 5.1$ & $20.2 \pm 4.5$ & 0.20 \\
\hline Domestic & $18.8 \pm 15.2$ & $20.8 \pm 12.3$ & 3.28 & $18.3 \pm 15.0$ & $21.7 \pm 12.2$ & 4.07 & $19.0 \pm 14.2$ & $21.0 \pm 13.5$ & 4.15 & $17.8 \pm 15.3$ & $20.2 \pm 11.5$ & 4.95 \\
\hline Sport & $3.8 \pm 2.6$ & $4.1 \pm 2.1$ & -0.09 & $3.9 \pm 2.5$ & $4.0 \pm 2.2$ & -0.32 & $4.1 \pm 2.5$ & $3.7 \pm 2.2$ & -0.69 & $3.8 \pm 2.5$ & $4.1 \pm 2.2$ & -0.22 \\
\hline Leisure & $1.3 \pm 2.1$ & $1.6 \pm 1.8$ & 0.32 & $1.3 \pm 2.0$ & $1.6 \pm 1.8$ & 0.58 & $1.4 \pm 2.1$ & $1.5 \pm 1.6$ & 0.28 & $1.2 \pm 2.0$ & $1.6 \pm 1.8$ & 0.52 \\
\hline Total & $44.3 \pm 15.4$ & $46.9 \pm 12.5$ & 4.09 & $43.6 \pm 14.8$ & $48.9 \pm 12.9$ & $5.58^{*}$ & $44.3 \pm 14.1$ & $47.4 \pm 13.9$ & 5.34 & $43.4 \pm 15.1$ & $48.2 \pm 12.4$ & $6.18^{*}$ \\
\hline
\end{tabular}

Note: $B$ = regression coefficient derived from the GEE model with adjustment for age at baseline, $\mathrm{FEV}_{1}$ predicted at each visit, smoking status, and whether the window was open or not; obs = observation; ${ }^{\#}$ Normal: Daily mean or $24-\mathrm{h}$ maximum of $\mathrm{PM}_{10}$ is below $125 \mu \mathrm{g} / \mathrm{m}^{3}$, and that of $\mathrm{PM}_{2.5}$ is below $35 \mu \mathrm{g} / \mathrm{m}^{3}$; * $\mathrm{Abnormal}$ : Daily mean or $24-\mathrm{h}$ maximum of PM 10

is above $125 \mu \mathrm{g} / \mathrm{m}^{3}$, and that of $\mathrm{PM}_{2.5}$ is above of $35 \mu \mathrm{g} / \mathrm{m}^{3} ; * p<0.05$ 


\subsection{Association between $P M\left(P M_{2.5}\right.$ and $\left.P M_{10}\right)$ and Acute Exacerbation of COPD}

Table 4 displays the number and rate of ER visits and admissions due to AE of COPD according to normal or abnormal PM levels, including $\mathrm{PM}_{2.5}$ and $\mathrm{PM}_{10}$. No events were recorded for normal $\mathrm{PM}_{2.5}$ levels. Therefore, the parameters of GEE analysis could not be converged. For $\mathrm{PM}_{10}$, the event rates (of both ER visits and admissions) were significantly higher in the abnormal group than in the normal group at all four areas (all $p<0.01$ ).

Table 4. Association between particulate matter $\left(\mathrm{PM}_{2.5}\right.$ and $\left.\mathrm{PM}_{10}\right)$ and acute exacerbation in COPD patients.

\begin{tabular}{|c|c|c|c|c|c|c|c|}
\hline \multirow{2}{*}{ Parameter } & \multirow{2}{*}{ No. of $o b s$} & \multicolumn{3}{|c|}{ Emergency Room (ER) Visit } & \multicolumn{3}{|c|}{$\begin{array}{l}\text { Admission Due to Acute Exacerbation } \\
\text { (AE) }\end{array}$} \\
\hline & & Event (\%) & OR $(95 \% \mathrm{CI})$ & $p$ & Event $(\%)$ & OR $(95 \%$ CI) & $p$ \\
\hline \multicolumn{8}{|l|}{$\mathrm{PM}_{2.5}$} \\
\hline \multicolumn{8}{|l|}{ Outdoor } \\
\hline Normal $^{\#}$ & 6 & $0(0.0)$ & Reference & - & $0(0.0)$ & Reference & - \\
\hline Abnormal * & 77 & $26(33.8)$ & NA & NA & $26(33.8)$ & NA & NA \\
\hline \multicolumn{8}{|l|}{ Living room } \\
\hline Normal $^{\#}$ & 9 & $0(0.0)$ & Reference & - & $0(0.0)$ & Reference & - \\
\hline Abnormal * & 74 & $26(35.1)$ & NA & NA & $26(35.1)$ & NA & NA \\
\hline \multicolumn{8}{|l|}{ Bedroom } \\
\hline Normal $\#$ & 13 & $0(0.0)$ & Reference & - & $0(0.0)$ & Reference & - \\
\hline Abnormal * & 70 & $26(37.1)$ & NA & NA & $26(37.1)$ & NA & NA \\
\hline \multicolumn{8}{|l|}{ Kitchen } \\
\hline Normal $^{\#}$ & 7 & $0(0.0)$ & Reference & - & $0(0.0)$ & Reference & - \\
\hline Abnormal * & 76 & $26(34.2)$ & NA & NA & $26(34.2)$ & NA & NA \\
\hline \multicolumn{8}{|l|}{$\mathrm{PM}_{10}$} \\
\hline \multicolumn{8}{|l|}{ Outdoor } \\
\hline Normal \# & 43 & $3(7.0)$ & Reference & - & $3(7.0)$ & Reference & - \\
\hline Abnormal * & 40 & $23(57.5)$ & $30.1(4.9-184.2)$ & $<0.001$ & $23(57.5)$ & $19.5(4.7-80.6)$ & $<0.001$ \\
\hline \multicolumn{8}{|l|}{ Living room } \\
\hline Normal ${ }^{\#}$ & 46 & $4(8.7)$ & Reference & - & $5(10.9)$ & Reference & - \\
\hline Abnormal * & 37 & $22(59.5)$ & $23.8(3.0-191.3)$ & 0.003 & $21(56.8)$ & $16.2(3.1-84.9)$ & 0.001 \\
\hline \multicolumn{8}{|l|}{ Bedroom } \\
\hline Normal $^{\#}$ & 50 & $7(14.0)$ & Reference & - & $7(14.0)$ & Reference & - \\
\hline Abnormal * & 33 & 19 (57.6) & $12.1(2.5-60.0)$ & 0.002 & $19(57.6)$ & $10.5(2.5-44.6)$ & 0.001 \\
\hline \multicolumn{8}{|l|}{ Kitchen } \\
\hline Normal $^{\#}$ & 46 & $3(6.5)$ & Reference & - & $4(8.7)$ & Reference & - \\
\hline Abnormal * & 37 & $23(62.2)$ & $38.5(4.8-311.8)$ & 0.001 & $22(59.5)$ & $18.5(3.7-91.9)$ & $<0.001$ \\
\hline
\end{tabular}

\section{Discussion}

We found that abnormal $\mathrm{PM}_{2.5}$ concentrations measured outdoors, in the living room, and in the kitchen were linked to increased wheezing symptoms among patients with moderate to very severe COPD, similar to the findings of Hansel et al. [27], but different from those of Kaji et al. [28]. Kaji et al. reported that an increase of $10 \mu \mathrm{g} / \mathrm{m}^{3}$ of $\mathrm{PM}_{2.5}$ was associated with an increase of dyspnea (Modified Medical Research Council score), cough, and phlegm [28]. We also found higher abnormal outdoor $\mathrm{PM}_{2.5}$ concentrations were associated with higher CAT physical scores, indicating increased fine PM concentrations might be associated with worse respiratory symptoms in general. Higher abnormal $\mathrm{PM}_{10}$ concentrations measured in the living room and in the kitchen were associated with increased wheezing symptoms and reduced ADL.

Our results showed no association between $\mathrm{PM}_{2.5}$ and $\mathrm{PM}_{10}$ concentrations in the bedroom and respiratory symptoms. One possibility is that there were lower abnormal rates and concentrations 
of $\mathrm{PM}_{2.5}$ and $\mathrm{PM}_{10}$ in the bedroom. A 2014 study on sources of $\mathrm{PM}_{2.5}$ and outdoor air in Santiago, Chile found that the two main sources of $\mathrm{PM}_{2.5}$ were emissions of traffic and cooking at home [29]. Therefore, another reason may be that the two main sources of $\mathrm{PM}_{2.5}$ in the living room were emissions of traffic (outdoor) and cooking at home (kitchen), resulting in different PM characteristics between the bedroom and other areas. Moreover, our sample size may have been too small. We also found that outdoor $\mathrm{PM}_{2.5}$ concentrations were associated with wheezing, but did not find an association between outdoor $\mathrm{PM}_{10}$ and wheezing. The reason for this difference was the different particle size. For $\mathrm{PM}_{2.5}$, long residence times and high indoor-outdoor penetration efficiencies resulted in indoor-outdoor associations. However, $\mathrm{PM}_{10}$ had high deposition rates and low penetration efficiencies, meaning that outdoor $\mathrm{PM}_{10}$ may not be able to penetrate indoors [30].

We also found that higher abnormal $\mathrm{PM}_{10}$ concentrations increased the risk of $\mathrm{AE}$ of COPD. These data suggest that higher PM concentration levels were related to worse COPD health, and COPD patients may be susceptible to the effect of PM. Recent epidemiological evidence showed that ambient PM is directly associated with mortality of COPD [4], as well as with AE of COPD [5-8]. Few studies have focused on examining the effect of indoor air quality on COPD patients, such as quality of life and lung function $[27,28,31-34]$. A study including 148 patients with severe COPD reported that the levels of $\mathrm{PM}_{2.5}$ were associated with a worse quality of life [31]. Other studies, including 35 and 17 patients with severe COPD, showed no association between $\mathrm{PM}_{2.5}$ and $\mathrm{PM}_{2.5-10}$ and lung function [33,34]. In addition to assessing the relationship between indoor air quality and lung function, Hansel et al. investigated the health effects of $\mathrm{PM}_{2.5}$ on COPD patients using comprehensive clinical assessments, including lung function, respiratory symptoms, quality of life, and exacerbations [27]. The authors reported that higher levels of $\mathrm{PM}_{2.5}$ were associated with increased respiratory symptoms, which is consistent with our present findings. We did not find an association between $\mathrm{PM}_{2.5}$ and $\mathrm{AE}$ of COPD after controlling for lung function at each visit, age at baseline, smoking status, and whether the window was open or not. However, again, our sample size may have been too small. In addition, $\mathrm{Xu}$ et al. (2016) [35] reported a strong association between increases in PM concentration on the day prior to or on the third day after emergency room visits for COPD patients. The use of categorical data (normal vs. abnormal) might be another possible explanation for our different findings.

Our study has some limitations. First, our study only included 19 COPD patients and 83 observations. It may not be generalizable to the COPD population at large, and further well-powered studies are needed to obtain more precise findings. Second, the level of indoor PM varies depending on who is living in the home and on visitor characteristics and/or behaviors [29]. We did not use a personal exposure device to measure PM. We only measured PM concentrations in a short period of time, which may not represent long-term exposure. We also did not analyze the composition of PM. Future studies should analyze the composition of PM in order to identify the source of air pollution.

\section{Conclusions}

Our study shows that elevated PM concentrations are associated with worse respiratory symptoms and increased risk of COPD exacerbations in patients with moderate to very severe COPD. With only 19 patients in the study, conclusions might be not warranted. To our knowledge, this is the first longitudinal study to investigate the adverse respiratory health effects of exposure to indoor PM on COPD patients in Taiwan. Future studies are needed to determine the effectiveness of environmental interventions or self-management programs to reduce PM concentrations and improve health outcomes in this susceptible population.

Acknowledgments: The authors gratefully acknowledge the financial support from the Chang Gung Medical Foundation of Taiwan (CMRPF6C0071, CMRPF6B0071, \& CMRPF6C0081). The authors also would like to thank Chiayi Chang Gung hospital, and all COPD patients who participated in this study for their valuable contributions.

Author Contributions: Su-Er Guo developed the concept and designed the study. Su-Er Guo and Miao-Ching Chi performed the data analyses. All authors contributed to the interpretation of the results and the final version of the manuscript. All authors read and approved the final manuscript. 
Conflicts of Interest: The authors declare no conflict of interest.

\section{References}

1. World Health Organization (WHO). Ambient (Outdoor) Air Quality and Health; WHO: Geneva, Switzerland, 2014.

2. Mannucci, P.M.; Harari, S.; Martinelli, I.; Franchini, M. Effects on health of air pollution: A narrative review. Intern. Emerg. Med. 2015, 10, 657-662. [CrossRef] [PubMed]

3. Dominici, F.; Peng, R.D.; Bell, M.L.; Pham, L.; Mcdermott, A.; Zeger, S.L.; Samet, J.M. Fine particulate air pollution and hospital admission for cardiovascular and respiratory diseases. JAMA 2006, 295, 1127-1134. [CrossRef] [PubMed]

4. Zanobetti, A.; Bind, M.A.; Schwartz, J. Particulate air pollution and survival in a COPD cohort. Environ. Health 2008, 7, 48. [CrossRef] [PubMed]

5. Chan, C.C.; Chuang, K.J.; Chen, W.J.; Chang, W.T.; Lee, C.T.; Peng, C.M. Increasing cardiopulmonary emergency visits by long-rang transported Asian dust storms in Taiwan. Environ. Res. 2008, 106, 393-400. [CrossRef] [PubMed]

6. Medina-Ramon, M.; Zanobetti, A.; Schwartz, J. The effect of ozone and $\mathrm{PM}_{10}$ on hospital admissions for pneumonia and chronic obstructive pulmonary disease: A national multicity study. Am. J. Epidemiol. 2006, 163, 579-588. [CrossRef] [PubMed]

7. Peacock, J.L.; Anderson, H.R.; Bremner, S.A.; Marston, L.; Seemungal, T.A.; Strachan, D.P.; Wedzicha, J.A. Outdoor air pollution and respiratory health in patients with COPD. Thorax 2011, 66, 591-596. [CrossRef] [PubMed]

8. Hwang, S.L.; Guo, S.E.; Chi, M.C.; Chou, C.T.; Lin, C.M.; Lin, Y.C. Association between Atmospheric Fine Particulate Matter and Hospital Admissions for Chronic Obstructive Pulmonary Disease in Southwestern Taiwan: A Population-Based Study. Int. J. Environ. Res. Public Health 2016, 13, 366. [CrossRef] [PubMed]

9. Gugamsetty, B.; Wei, H.; Liu, C.N.; Awasthi, A.; Hsu, S.C.; Tsai, C.J.; Roam, G.D.; Wu, Y.C.; Chen, C.F. Source characterization and apportionment of $\mathrm{PM}_{10}, \mathrm{PM}_{2.5}$ and $\mathrm{PM}_{0.1}$ by using positive matrix factorization. Aerosol Air Qual. Res. 2012, 12, 476-491. [CrossRef]

10. Rabe, K.F.; Hurd, S.; Anzueto, A.; Barnes, P.J.; Buist, S.A.; Calverley, P.; Fukuchi, Y.; Jenkins, C.; Rodriguez-Roisin, R.; van Weel, C.; et al. Global strategy for the diagnosis, management, and prevention of chronic obstructive pulmonary disease: GOLD executive summary. Am. J. Respir. Crit. Care Med. 2007, 176, 532-555. [CrossRef] [PubMed]

11. Miravitlles, M.; Ferrer, M.; Pont, A.; Zalacain, R.; Alvarez-Sala, J.L.; Masa, F.; Verea, H.; Murio, C.; Ros, F.; Vidal, R.; et al. Effect of exacerbations on quality of life in patients with chronic obstructive pulmonary disease: A 2 year follow up study. Thorax 2004, 59, 387-395. [CrossRef] [PubMed]

12. Seemungal, T.A.; Donaldson, G.C.; Paul, E.A.; Bestall, J.C.; Jeffries, D.J.; Wedzicha, J.A. Effect of exacerbation on quality of life in patients with chronic obstructive pulmonary disease. Am. J. Respir. Crit. Care Med. 1998, 157, 1418-1422. [CrossRef] [PubMed]

13. Miravitlles, M.; Murio, C.; Guerrero, T.; Gisbert, R. Pharmacoeconomic evaluation of acute exacerbations of chronic bronchitis and COPD. Chest 2002, 121, 1445-1455. [CrossRef]

14. Global Initiative for Chronic Obstructive Lung Disease (GOLD). Pocket Guide to COPD Diagnosis, Management, and Prevention, Update 2015: A Guide for Health Care Professionals. Available online: http://www.neumo-argentina.org/images/guias_consensos/gold_pocket_2015.pdf (accessed on 21 August 2016).

15. Donaldson, G.C.; Seemungal, T.A.; Bhowmik, A.; Wedzicha, J.A. Relationship between exacerbation frequency and lung function decline in chronic obstructive pulmonary disease. Thorax 2002, 57, 847-852. [CrossRef] [PubMed]

16. Global Initiative for Chronic Obstructive Lung Disease (GOLD). Global Strategy for the Diagnosis, Management, and Prevention of Chronic Obstructive Pulmonary Disease (Update 2016). Available online: http://goldcopd.org/global-strategy-diagnosis-management-prevention-copd-2016/ (accessed on 15 September 2016). 
17. Alahmari, A.D.; Patel, A.R.; Kowlessar, B.S.; Mackay, A.J.; Singh, R.; Wedzicha, J.A.; Donaldson, G.C. Daily activity during stability and exacerbation of chronic obstructive pulmonary disease. BMC Pulm. Med. 2014, 14, 98. [CrossRef] [PubMed]

18. Parker, C.M.; Voduc, N.; Aaron, S.D.; Webb, K.A.; O’Donnell, D.E. Physiological changes during symptom recovery from moderate exacerbations of COPD. Eur. Respir. J. 2005, 26, 420-428. [CrossRef] [PubMed]

19. World Health Organization (WHO). The Top 10 Causes of Death; WHO: Geneva, Switzerland, 2014.

20. Ministry of Health and Welfare, Executive Yuan. 2014 Death Causes Annual Report in Statistics; Ministry of Health and Welfare, Executive Yuan: Taipei City, Taiwan, 2016.

21. Accounting and Statistics Department, Chiayi County Government. 10 Leading Causes of Death; Accounting and Statistics Department, Chiayi County Government: Puzi City, Taiwan, 2016.

22. Yeh, C.Y. Measuring Quality of life in Patients with Chronic Obstructive Pulmonary Disease (COPD): Evaluating the Performance of the SGRQ. New Taipei J. Nurs. 2002, 4, 19-28.

23. Chai, J.J.; Liu, T.; Cai, B.Q. Evaluation of clinical significance of chronic obstructive pulmonary disease assessment test. Chin. J. Tuberc. Respir. Dis. 2011, 34, 256-258.

24. Garrod, R.; Bestall, J.C.; Paul, E.A.; Wedzicha, J.A.; Jones, P.W. Development and validation of a standardized measure of activity of daily living in patients with severe COPD: The London chest activity of daily living scale (LCADL). Respir. Med. 2000, 94, 589-596. [CrossRef] [PubMed]

25. Environmental Protection Administration, Executive Yuan. Air Quality Standards; Environmental Protection Administration, Executive Yuan: Taipei City, Taiwan, 2016.

26. Liang, K.Y.; Zeger, S.L. Longitudinal analysis using generalized linear models. Biometrika 1986, 73, 13-22. [CrossRef]

27. Hansel, N.N.; McCormack, M.C.; Belli, A.J.; Matsui, E.C.; Peng, R.D.; Aloe, C.; Paulin, L.; Williams, D.L.; Diette, G.B.; Breysse, P.N. In-home air pollution is linked to respiratory morbidity in former smokers with chronic obstructive pulmonary disease. Am. J. Respir. Crit. Care Med. 2013, 187, 1085-1090. [CrossRef] [PubMed]

28. Kaji, D.A.; Belli, A.J.; McCormack, M.C.; Matsui, E.C.; Williams, D.L.; Paulin, L.; Putcha, N.; Peng, R.D.; Diette, G.B.; Breysse, P.N.; et al. Indoor pollutant exposure is associated with heightened respiratory symptoms in atopic compared to non-atopic individuals with COPD. BMC Pulm. Med. 2014, 14, 147. [CrossRef] [PubMed]

29. Barraza, F.; Hector, J.; Gonzalo, V.; Montoya, L.D. Indoor $\mathrm{PM}_{2.5}$ in Santiago, Chile, spring 2012: Source apportionment and outdoor contributions. Atmos. Environ. 2014, 94, 692-700. [CrossRef]

30. Rojas-Bracho, L.; Suh, H.H.; Koutrakis, P. Relationships among personal, indoor, and outdoor fine and coarse particle concentrations for individuals with COPD. J. Expo. Anal. Environ. Epidemiol. 2000, 10, $294-306$. [CrossRef] [PubMed]

31. Osman, L.M.; Douglas, J.G.; Garden, C.; Reglitz, K.; Lyon, J.; Gordon, S.; Ayres, J.G. Indoor air quality in homes of patients with chronic obstructive pulmonary disease. Am. J. Respir. Crit. Care Med. 2007, 176, 465-472. [CrossRef] [PubMed]

32. Fong, K.N.; Mui, K.W.; Chan, W.Y.; Wong, L.T. Air quality influence on chronic obstructive pulmonary disease (COPD) patients' quality of life. Indoor Air 2010, 20, 434-441. [CrossRef] [PubMed]

33. De Hartog, J.J.; Ayres, J.G.; Karakatsani, A.; Analitis, A.; Brink, H.T.; Hameri, K.; Harrison, R.; Katsouyanni, K.; Kotronarou, A.; Kavouras, I.; et al. Lung function and indicators of exposure to indoor and outdoor particulate matter among asthma and COPD patients. Occup. Environ. Med. 2010, 67, 2-10. [CrossRef] [PubMed]

34. Hsu, S.O.; Ito, K.; Lippmann, M. Effects of thoracic and fine PM and their components on heart rate and pulmonary function in COPD patients. J. Expo. Sci. Environ. Epidemiol. 2011, 21, 464-472. [CrossRef] [PubMed]

35. Xu, Q.; Li, X.; Wang, S.; Wang, C.; Huang, E.; Gao, Q.; Wu, L.; Tao, L.; Guo, J.; Wang, W.; et al. Fine Particulate Air Pollution and Hospital Emergency Room Visits for Respiratory Disease in Urban Areas in Beijing, China, in 2013. PLoS ONE 2016, 11, e0153099. [CrossRef] [PubMed]

(C) 2016 by the authors; licensee MDPI, Basel, Switzerland. This article is an open access article distributed under the terms and conditions of the Creative Commons Attribution (CC-BY) license (http://creativecommons.org/licenses/by/4.0/). 